\title{
Canopy structure and topography effects on snow distribution at a catchment scale: Application of multivariate approaches
}

\author{
Michal Jenicek*, Hana Pevna, Ondrej Matejka \\ Department of Physical Geography and Geoecology, Faculty of Science, Charles University, Albertov 6, 12843 Prague, Czech Republic. \\ * Corresponding author. E-mail: michal.jenicek@natur.cuni.cz
}

\begin{abstract}
The knowledge of snowpack distribution at a catchment scale is important to predict the snowmelt runoff. The objective of this study is to select and quantify the most important factors governing the snowpack distribution, with special interest in the role of different canopy structure. We applied a simple distributed sampling design with measurement of snow depth and snow water equivalent (SWE) at a catchment scale. We selected eleven predictors related to character of specific localities (such as elevation, slope orientation and leaf area index) and to winter meteorological conditions (such as irradiance, sum of positive air temperature and sum of new snow depth). The forest canopy structure was described using parameters calculated from hemispherical photographs. A degree-day approach was used to calculate melt factors. Principal component analysis, cluster analysis and Spearman rank correlation were applied to reduce the number of predictors and to analyze measured data. The SWE in forest sites was by $40 \%$ lower than in open areas, but this value depended on the canopy structure. The snow ablation in large openings was on average almost two times faster compared to forest sites. The snow ablation in the forest was by $18 \%$ faster after forest defoliation (due to the bark beetle). The results from multivariate analyses showed that the leaf area index was a better predictor to explain the SWE distribution during accumulation period, while irradiance was better predictor during snowmelt period. Despite some uncertainty, parameters derived from hemispherical photographs may replace measured incoming solar radiation if this meteorological variable is not available.
\end{abstract}

Keywords: Snowpack distribution; Canopy structure; Leaf area index; Degree-day; Bark beetle.

\section{INTRODUCTION}

Snow is an important component of hydrological cycle in many world's catchments. A significant quantity of water is stored in the form of snow during cold period causing higher runoff during spring. This higher runoff may cause floods and thus it forms a potential danger for people living near the rivers. Therefore, the knowledge of water volume stored in the snowpack and its spatial distribution represents the basic information for hydrological forecasting.

The snow storage is determined by the spatial distribution of snow water equivalent (SWE), which is mostly controlled by the spatial distribution of snow depth (Seibert et al., 2014). Large-scale variations of snow storage are controlled by air temperature, which is related to elevation and latitude (Kucerova and Jenicek, 2014; Molotch and Meromy, 2014). However, at smaller scales, the snow accumulation and snowmelt are more driven by topography and vegetation (Grünewald et al., 2013; Jenicek et al., 2012, 2017; Šípek and Tesař, 2014). Stähli and Gustafsson (2006) found that, over a long-term period, the annual SWE maximum is by up to $50 \%$ higher in open areas than in the forest. However, this effect decreases with increasing snow accumulations. The differences between snow storages accumulated in open areas and in forests with different structure were reported from many other world's areas (Lundquist et al., 2013; Revuelto et al., 2016).

The forest influences snow storage on canopy (snow interception), snow redistribution due to wind and the density of snowpack during snow accumulation, depending mainly on forest type (coniferous, deciduous) and on structure influencing canopy leaf area index (LAI). The snow interception affects snow accumulation under treetops (Garvelmann et al., 2013; Holko et al., 2009; Stähli et al., 2009; Strasser et al., 2011). Additionally, the forest influences turbulent fluxes (Pohl et al.,
2006) and reduces the amount of short-wave solar radiation and thus snowmelt rates (Pomeroy et al., 2012; Schnorbus and Alila, 2013). The proportion of longwave and shortwave radiation varies depending on yearly climatic conditions and thermal regime of the study site (Lundquist et al., 2013). The longwave radiation under forest canopy is relatively more important than incoming shortwave radiation especially in mid-winter because it causes faster snowmelt compared to adjacent open area. This occurs because the efficiency of forest to reduce incoming shortwave radiation is most important during spring when the shortwave radiation is high enough (Lundquist et al., 2013; Schnorbus and Alila, 2013).

Although the effect of forest on the snowmelt volume is more driven by the energy budget of snowpack, the effect on runoff is more complex and it is strongly influenced, among others, by meteorological conditions at the beginning and during the snowmelt. As documented by Pomeroy et al. (2012), who performed a wide range of different hypothetical scenarios at Marmot Creek in Canada, the total spring and summer runoff volume increases by less than $10 \%$ in case of forest burning and logging, however, the snowmelt volume increases by $45 \%$. The mentioned study also showed that burning and pine beetle impacts affect more peak flows than seasonal runoff volumes (by up to $25 \%$ ). The effect of clear-cutting is documented by Schelker et al. (2013) for a catchment in northern Sweden. They observed that the SWE increased after clear-cutting by $30 \%$, snowmelt occurred earlier and spring flood runoff increased significantly in some years.

The bark beetle (Ips typographus) outbreak occurs in the Sumava Mountains (Bohemian Forest) and the Bavarian Forest national parks in the Czech Republic, Germany and Austria. It is a natural disaster affecting large areas of Norway spruce forest (Picea abies). Both windstorms and the bark beetle are the main factors causing land cover changes in the Sumava 
Mountains, which have an effect on interception, evaporation and consequently runoff (Kliment et al., 2011; Langhammer et al., 2015a; Vlcek et al., 2012). The bark beetle causes tree defoliation. Therefore, snow interception becomes less important which results in snow storages increase. However, the difference between snow stored under healthy and disturbed forest become less important in snow-rich years because the large snowfalls exceed the interception capacity of the canopy (Boon, 2012).

On the contrary, snow melts faster due to the decreasing canopy shading effect and thus the increasing solar radiation. Additionally, ongoing climate changes and consequent changes of winter and spring runoff represent positive feedback and might further underline the impact of land cover changes on runoff (Blahušiaková and Matoušková, 2015; Langhammer et al., 2015b).

The assessment of the effect of different forest structures and forest disturbances on snow accumulation and snowmelt is often done using suitable modelling approaches, as it is usually less time and costly demanding than field observations (Essery et al., 2009, 2013; Jost et al., 2012; Kutlakova and Jenicek, 2012; Pomeroy et al., 2012). However, field data bridge the gap between the real physical process and its conceptualization using suitable equation and parameters. Based on measured or simulated data, it is possible to estimate the effect of forest disturbances on snowmelt dynamics, such as windstorms, fires and insect attacks (Burles and Boon, 2011; Pomeroy et al., 2012; Pugh and Small, 2013; Winkler et al., 2015).

The objective of our study was to quantify the role of main factors governing the snowpack distribution at a catchment scale during snow accumulation and snow ablation periods. More specifically, we tested different bivariate and multivariate statistical approaches to select key controls influencing snow characteristics using meteorological, topography and vegetation data which are relatively easy to derive from climate observations, digital terrain model and land cover data. Although, we are aware that snow ablation is driven by the complex energy balance, our aim was to apply simple procedures to enable easier application in areas without detailed meteorological monitoring. This is not a new topic, but our study focuses more on the effect of different canopy structure (including disturbed forest due to the bark beetle) during both snow accumulation and snow abla- tion period. We chose a simple distributed sampling design and we benefit from a large data set sampled at 16 localities for five years covering a wide range of snow conditions.

\section{MATERIAL AND METHODS Study area and data monitoring}

We performed detailed field survey of snow depth, snow density and SWE in small mountain catchment of Ptaci Brook $\left(4 \mathrm{~km}^{2}\right)$, which is an experimental catchment of the Charles University (Fig. 1). The Ptaci Brook catchment is located in the Sumava Mountains (Bavarian forest) in the southwest part of the Czech Republic. The catchment is located from 1130 to $1330 \mathrm{~m}$ a.s.l. with prevailing west, north and east oriented slopes with mean slope gradient $6^{\circ}$ (with maximum up to $30^{\circ}$ ). The dominant tree species is Norway spruce (Picea abies), although large parts of forests were damaged by the bark beetle (Ips typographus). Vegetation changes are still largely occurring until now.

Data from three meteorological stations were used in this study. First two of them (Ptaci Brook and Breznik) are operated by the Charles University using the same instrumentation as deployed by the national observation network of the Czech Hydrometeorological Institute. The Ptaci Brook station is located directly in the study area (sampling site "15, 16", see Fig. 1) and the Breznik station is located $1.5 \mathrm{~km} \mathrm{~W}$ from the study area at the same elevation as sampling sites. The third station is operated by German Weather Service (DWD) and it is located $28 \mathrm{~km} \mathrm{NW}$ from the study area 100-250 m higher than sampling sites. The air temperature, global radiation and snow depth (using ultrasonic sensor) measured every 10 minutes were adjusted to daily resolution and used to calculate predictor variables (see the part "Predictors and response variables"). Data from several stations were used because of gaps in time series of the Ptaci Brook station which would otherwise be most appropriate to calculate all predictors.

\section{Sampling strategy}

We chose simple distributed sampling design with location placed uniformly in the catchment and covering major topography and vegetation characteristics typical for the study area.

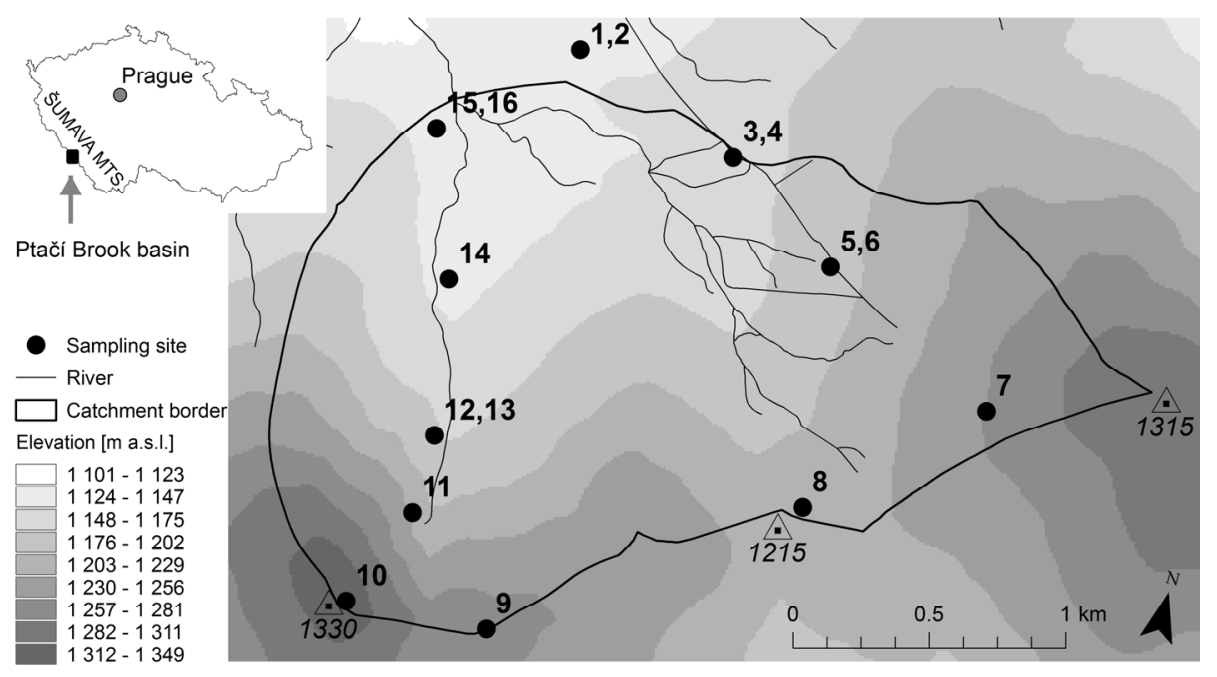

Fig. 1. Geographical location of the Ptaci Brook basin. Black dots indicate sampling sites. Two numbers at one location indicate paired measuring of snow depth and SWE in open area/clearing and in forest. The position of Ptačí Brook meteorological station corresponds with location " 15,16 ". 
The snow depth and SWE were sampled at 16 sites either in forest or in open area/clearing (Fig. 1). In total, we used data from 6 forest sites (including 3 forested sites affected by the bark beetle), 5 clearings (small open areas protected from solar radiation and wind by surrounding trees in maximum distance up to triple of the trees height) and 5 large open areas. At each sampling site, the snow depth was measured 5 times along $50 \mathrm{~m}$ long transect in regular step. Each from the five snow depth values was calculated as an average from 10 individual measurements with a probe to avoid possible errors due to small scale topography, stones and ground vegetation. The SWE was measured 2 times along the same transect using a snow tube. Basic characteristics of all 16 sampling sites are displayed in Fig. 2, individual characteristics are explained in the section "Predictors and response variables".

Manual field surveys of snow depth and SWE were carried out fourteen times during five winter seasons from 2011 to 2015 (Table 1). Different climatic conditions in each winter enable us to measure the data during different snow conditions, such as early winter snow accumulations with low snow densities, mid-winter accumulations with or without partial melting caused by rain-on-snow events and high snow densities during snowmelt periods. The evolution of snow depth in all winter seasons is displayed in Fig. 3.

\section{Predictors and response variables}

We selected eleven predictors related to sampling site characteristics and to winter and spring meteorological conditions (Table 2). These predictors were used to explain the variability of snow accumulation and ablation in the study area.

Elevation and slope were expressed as real values (in $\mathrm{m}$ a.s.l., respectively in decimal degrees) calculated from digital terrain model. The slope orientation (aspect) was recalculated as transformed aspect (Eq. 1).

Transformed_aspect $=\left(\sin \left(\operatorname{aspect}_{\mathrm{rad}}-(\pi / 2)\right)+1\right) / 2$

Equation 1 transforms aspects into values ranging from 0 to 1. Value 1 represents south orientation, value 0 represents north orientation and 0.5 represents both east and west orientations. A similar approach was used by Jost et al. (2007).

The influence of vegetation on the snowpack distribution was described using parameters derived from hemispherical images of the sky and canopy: i) LAI (often known as LAI4 which considers $60^{\circ}$ wide sector from zenith), ii) percentage rate of pixels representing canopy to pixels representing sky (canopy openness) and iii) the potential amount of shortwave radiation calculated as a sum from November 1 to April 30 (potential irradiance). Overall, 32 hemispherical images were taken in the study area (two at each site). All images were taken during one day. The images were taken using camera with fisheye lens (Sigma Circular Fisheye with focal length $4.5 \mathrm{~mm}$ ) and analyzed using Gap Light Analyzer software (Frazer et al., 1999). Geographical coordinates, elevation and digital terrain model (used for shading effect calculation) were used as input data for each locality. All variables needed for calculations were set up as shown in Table 3 . We tested different values of cloudiness index and found no impact on resulting correlations since we analyzed relative differences of potential irradiance between individual sampling sites/dates. Frazer et al. (1999) provide more information regarding the above variables.

The use of only two hemispherical images per one locality may produce a random error in calculation of the specific parameter. Therefore, we chose three sites in different land covers where we took 25 images in regular grid $25 \times 25 \mathrm{~m}$ (with $5 \mathrm{~m}$ step) and assessed their variability using coefficient of variation $C_{\mathrm{v}}$.
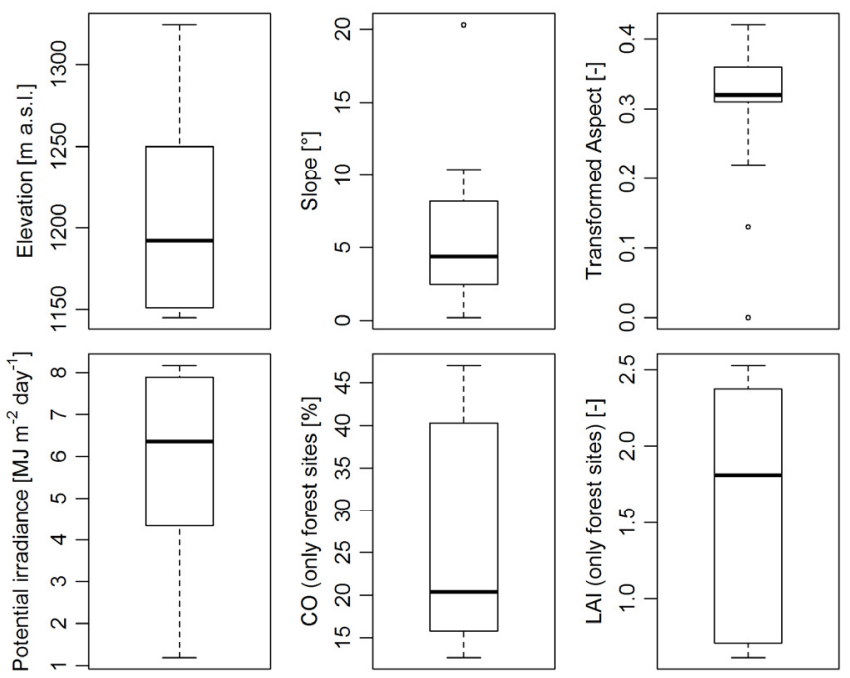

Fig. 2. Basic characteristics of 16 sampling sites. $\mathrm{CO}$ is the canopy openness; LAI is the Leaf area index. Individual characteristics are explained in the text.

Table 1. Dates of data sampling and related characteristics. Column "Snowmelt" indicates snow accumulation or snowmelt conditions during data sampling. The total irradiance represents the irradiance for open areas (without shading effect of vegetation). Individual characteristics are explained in the text.

\begin{tabular}{|c|c|c|c|c|c|c|c|c|}
\hline Date & Snowmelt & $\begin{array}{c}\text { Mean SWE } \\
{[\mathrm{mm}]}\end{array}$ & $\begin{array}{l}\text { Range } \\
{[\mathrm{mm}]}\end{array}$ & $\begin{array}{l}\text { Mean snow } \\
\text { depth }[\mathrm{cm}]\end{array}$ & $\begin{array}{l}\text { Mean snow } \\
\text { density }[-]\end{array}$ & $\begin{array}{c}\text { Sum of } \mathrm{T}^{+} \\
{\left[{ }^{\circ} \mathrm{C}\right]}\end{array}$ & $\begin{array}{c}\text { Sum of new } \\
\text { SD }[\mathrm{cm}]\end{array}$ & $\begin{array}{l}\text { Total irradiance } \\
{\left[\mathrm{MJ} \mathrm{m}^{-2} \mathrm{~d}^{-1}\right]}\end{array}$ \\
\hline 19 Mar 2011 & No & 177 & $11-307$ & 49 & 0.36 & 99.4 & 253 & 846 \\
\hline 26 Mar 2011 & Yes & 152 & $69-266$ & 39 & 0.39 & 120.4 & 253 & 987 \\
\hline 29 Feb 2012 & No & 487 & $283-730$ & 139 & 0.35 & 28.7 & 324 & 539 \\
\hline 16 Mar 2012 & No & 457 & $215-696$ & 117 & 0.39 & 62.6 & 328 & 774 \\
\hline $24 \operatorname{Mar} 2012$ & Yes & 425 & $217-635$ & 100 & 0.42 & 101.9 & 328 & 935 \\
\hline 7 Apr 2012 & Yes & 305 & $19-499$ & 76 & 0.40 & 144.5 & 328 & 1170 \\
\hline 6 Mar 2013 & No & 296 & $97-467$ & 93 & 0.31 & 38.3 & 375 & 517 \\
\hline 16 Mar 2013 & No & 286 & $112-484$ & 80 & 0.35 & 56.2 & 384 & 646 \\
\hline 13 Apr 2013 & No & 302 & $110-503$ & 82 & 0.37 & 65.2 & 451 & 1002 \\
\hline 23 Apr 2013 & Yes & 137 & $0-374$ & 35 & 0.39 & 137.3 & 451 & 1215 \\
\hline 10 Mar 2014 & Yes & 112 & $0-238$ & 34 & 0.34 & 167.6 & 178 & 731 \\
\hline 18 Mar 2014 & Yes & 80 & $0-209$ & 22 & 0.36 & 203.8 & 193 & 848 \\
\hline 12 Mar 2015 & No & 169 & $40-257$ & 59 & 0.28 & 73.9 & 150 & 645 \\
\hline 23 Mar 2015 & Yes & 153 & $0-257$ & 48 & 0.32 & 93.7 & 153 & 823 \\
\hline
\end{tabular}




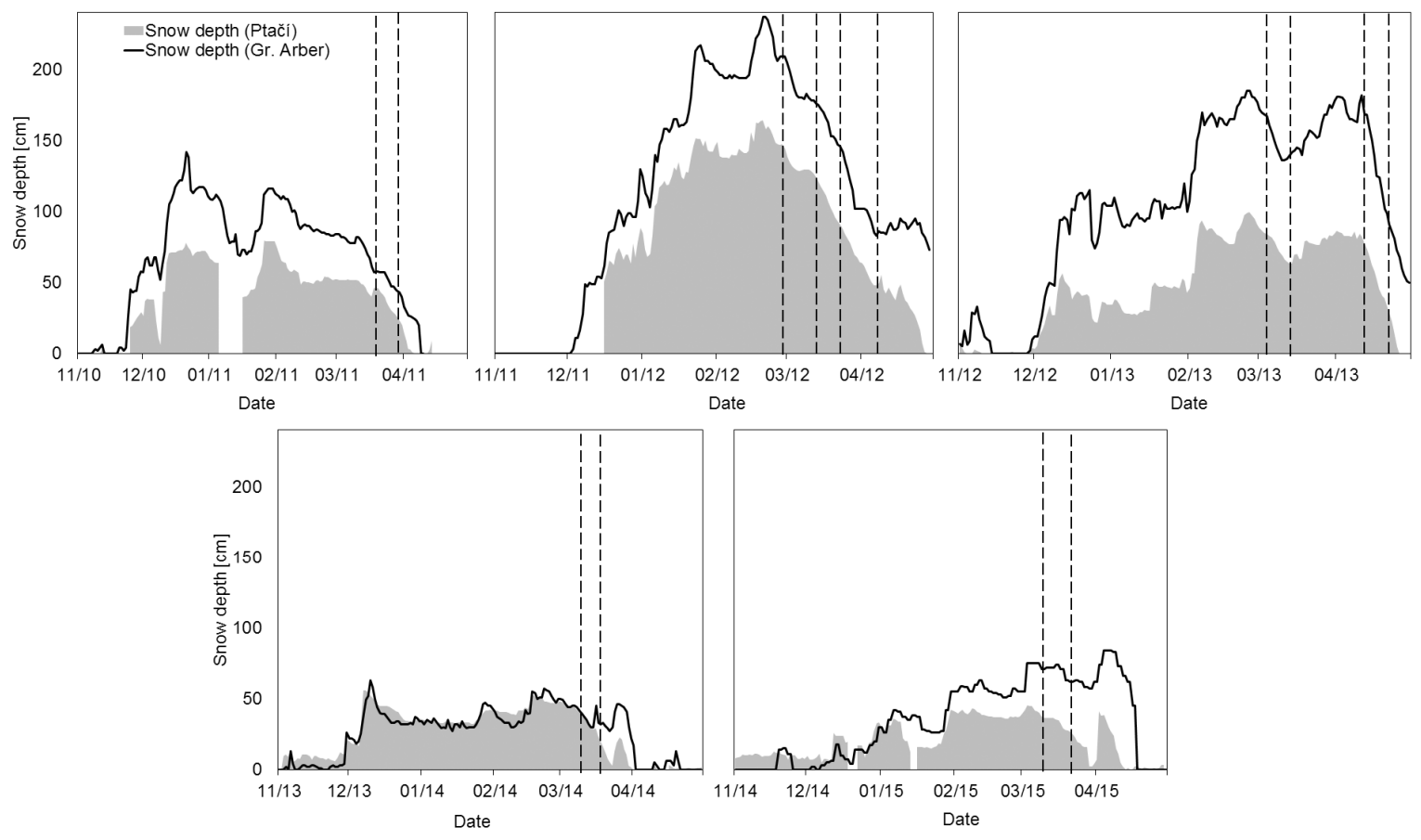

Fig. 3. The snow depth in winter seasons 2011-2015 measured in the Ptaci Brook meteorological station (grey areal plot, gaps indicate missing data) and Grosser Arber (Bavarian forest, solid line). Dashed vertical lines represent sampling dates. Data: Charles University and German Weather Service (DWD).

Table 2. Predictors and response variables used in analyses.

\begin{tabular}{|c|c|}
\hline Predictor variable & Response variable \\
\hline Elevation & Snow water equivalent (SWE) \\
\hline Slope & Snow depth (SD) \\
\hline Slope orientation (expressed as transformed aspect) & Snow density \\
\hline Leaf Area Index (LAI) & Melt factor $\mathrm{m}_{\mathrm{f}}$ calculated using the degree-day approach \\
\hline \multicolumn{2}{|l|}{ Canopy Openness } \\
\hline \multicolumn{2}{|l|}{$\begin{array}{l}\text { Potential amount of shortwave radiation at the site from November } 1 \text { to } \\
\text { April } 30 \text { (Potential irradiance) }\end{array}$} \\
\hline \multicolumn{2}{|l|}{$\begin{array}{l}\text { Irradiance at the site from start of snow accumulation to sampling date } \\
\text { (Total irradiance) }\end{array}$} \\
\hline \multicolumn{2}{|l|}{$\begin{array}{l}\text { Mean daily irradiance from preceding sampling date to sampling date } \\
\text { (Partial irradiance) }\end{array}$} \\
\hline \multicolumn{2}{|l|}{$\begin{array}{l}\text { Sum of new snow depth from start of accumulation to sampling date } \\
\text { (Sum of new SD) }\end{array}$} \\
\hline \multicolumn{2}{|l|}{$\begin{array}{l}\text { Sum of positive air temperature from start of accumulation to sampling } \\
\text { date }\left(\text { Sum of } \mathrm{T}^{+}\right)\end{array}$} \\
\hline Day of year of data sampling (DOY) & \\
\hline
\end{tabular}

Table 3. User input variables set up in the GLA software for hemispherical photos analysis.

\begin{tabular}{ll}
\hline User input variables & Value \\
\hline Cloudiness index & 0.5 \\
Spectral fraction $(0.25-25 \mathrm{~mm})$ & 1 \\
Beam fraction & 0.5 \\
Clear-sky transmission coefficient & 0.6 \\
Solar constant $\left[\mathrm{W} \mathrm{m}^{-2}\right]$ & 1367 \\
\hline
\end{tabular}

Resulting $C_{\mathrm{v}}$ showed that the variability does not significantly changed among individual land cover types for canopy openness and potential radiation in selected sites, although some variability of LAI within the plot scale increased for disturbed forest and for clearings.
The irradiance at the site from the start of snow accumulation to the sampling date (Total irradiance) represents the sum

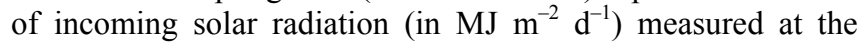
Breznik meteorological station. The total irradiance at the specific site was adjusted to represent conditions below forest canopy. To do this, the canopy openness calculated from respective hemispherical image was used as a multiplicative factor.

The mean daily irradiance from the preceding sampling date to the sampling date (Partial irradiance) represents mean daily sum of incoming solar radiation for each period of two succeeding surveys. This predictor was calculated from total irradiance and used for snowmelt assessment.

The sum of new snow depth (Sum of new SD) and the sum of positive air temperatures (Sum of $\mathrm{T}^{+}$) were used as parameters to describe the evolution of meteorological conditions 
during specific winter season. Both parameters were calculated from the beginning of snow accumulation to the day of field measurement as specified in Table 1 . Both variables were calculated using snow depth and air temperature from Grosser Arber meteorological station, where complete observations were available. Air temperature was adjusted to the sampling sites elevation using a lapse rate $0.6^{\circ} \mathrm{C} / 100 \mathrm{~m}$. The day of year of data sampling (DOY) was used to describe whether the response variable (especially snow density) changed during winter season.

The above described predictors were tested to explain the variability of four response variables describing snow conditions: i) SWE [mm], ii) snow depth [cm], iii) snow density [-] and iv) melt factor $m_{\mathrm{f}}$ (also known as degree-day factor) calculated from measured data according to the degree-day approach (Hock, 2003).

The degree-day approach represents the simplified energy balance of the snowpack, which is described using the air temperature and melt factor (Eq. 2).

$M=m_{\mathrm{f}}\left(T_{\mathrm{a}}-T_{\mathrm{c}}\right)$,

where $m_{\mathrm{f}}\left[\mathrm{mm}{ }^{\circ} \mathrm{C}^{-1} \mathrm{~d}^{-1}\right]$ is the melt or degree-day factor representing the SWE decrease in a day caused by the air temperature change $T_{\mathrm{a}}$ of $1{ }^{\circ} \mathrm{C}$ compared to the critical air temperature $T_{\mathrm{c}}$ in which the melting process begins.

The melt factors for different types of vegetation were calculated based on measured SWE decreases between two sampling dates. Only periods with zero or very small influence of precipitation were taken into account (the maximum daily precipitation between sampling dates was less than $2 \mathrm{~mm} /$ day, but typically near zero). In total, $78 m_{\mathrm{f}}$ values were analyzed from 2011 to 2015. Air temperature from two meteorological stations was used to calculate the melt factors. Lapse rates accounting for temperature change with elevation were calculated for each day and each sampling site. Critical temperature $T_{\mathrm{c}}$ was set up to $0^{\circ} \mathrm{C}$ in this study.

\section{Bivariate and multivariate statistical analyses}

The correlation analysis between snowpack properties and site characteristics was based on the assumption that the snowpack distribution depends on preceding meteorological conditions and site properties connected to vegetation structure and topography.

First, the correlation was assessed using Spearman rank correlation coefficients between predictors and response variables and displayed as correlation heat maps.

Second, the importance of both vegetation and topography parameters was additionally tested using Cluster Analysis. The whole dataset from all sampling campaigns was assessed either as a one set or divided into several subsets according to the vegetation classes. Each subset was put into hierarchical cluster analysis using the Euclidean distance as a measure of similarity. A similar procedure was used to evaluate similarity of individual sampling locations based on site characteristics related to topography (elevation, slope, slope orientation), vegetation (canopy openness, potential irradiance) and snowmelt dynamics (melt factor $m_{\mathrm{f}}$ ).

Finally, the relation between snow conditions and site characteristics was examined with Principal Component Analysis (PCA). The PCA is an explorative analysis which enables to reduce number of predictors and to classify them among principal components which capture the much of the variance of the original dataset (Fischer et al., 2015; López-Moreno and
Latron, 2008; Revuelto et al., 2016). A set of mutually correlated variables are transformed into a set of uncorrelated variables (principal components, PC) which are ordered by reducing variability. The PCs are linear combinations of the original variables. The PCs which explain a little variance can be removed with minimum loss of explanatory power of the original dataset. The transformed data are rotated such that maximum variability is projected onto the PCA axes using a biplot.

All predictors were expressed as normalized values using $\mathrm{z}-$ score (the mean is 0 , standard deviation is 1 ). The mutual independency of predictors was tested using Pearson correlation coefficient at 0.05 significance level. The R software (R Core Team, 2016) and Statistica software (http://www.statsoft.com/) were used for all calculations in this study.

\section{RESULTS \\ Multivariate analysis of selected predictors and response variables}

There are two groups of predictors used in this study which are necessary to be assessed separately. The first group is formed by predictors which are supposed to be time-invariant (such as topography and canopy structure). The second group of predictors is formed mostly by characteristics related to meteorological conditions and they are changing over the time both during one winter season and between seasons (sum of new SD, sum of $\mathrm{T}^{+}$and total irradiance). Therefore, Spearman rank correlation coefficients between predictors and response variables were calculated separately 1) for each sampling date and all sampling points using only time-invariant predictors (Fig. 4, left) and 2) for each locality using predictors which are changing in time (Fig. 4, right). The Spearman rank correlation coefficients were displayed as heat maps together with dendrograms showing clusters of similar predictors and response variables (Fig. 4).

The Spearman rank correlation coefficients calculated separately for individual sampling dates (Fig. 4, left) indicated high correlations of melt factors $m_{\mathrm{f}}$ with variables related to canopy structure as well as with partial irradiance calculated from previous sampling date. The correlation of $m_{\mathrm{f}}$ and partial irradiance was relatively high not only when comparing specific localities to each other for specific sampling date (Fig. 4, left), but also when comparing inter-annual variations of $m_{\mathrm{f}}$ at the specific site (Fig. 4, right).

All parameters related to vegetation structure were significantly correlated with snow depth, SWE and snow density both for snow accumulation and snowmelt periods, although the correlations for snow accumulation periods were a bit higher (Fig. 4, left). The LAI was better predictor to explain the SWE distribution during accumulation period; the total irradiance and potential irradiance were slightly better during snowmelt period. However, the differences are rather minor.

Similar to canopy characteristics and irradiance, the explanatory power of elevation was higher for response variables measured during snow accumulation period than during snowmelt. However, elevation was not significantly correlated to $m_{\mathrm{f}}$.

The slope orientation (expressed as transformed aspect) was not important to explain any of response variable. This is probably due to relatively low range of slope orientations with prevailing NW to NE slopes.

The sum of positive air temperatures (sum of $\mathrm{T}^{+}$) is important especially for the SWE and snow depth measured during both the snow accumulation and snowmelt period (Fig. 4, right). Especially for the snow accumulation period, the sum of $\mathrm{T}^{+}$seems to be an interesting parameter to explain inter-annual 

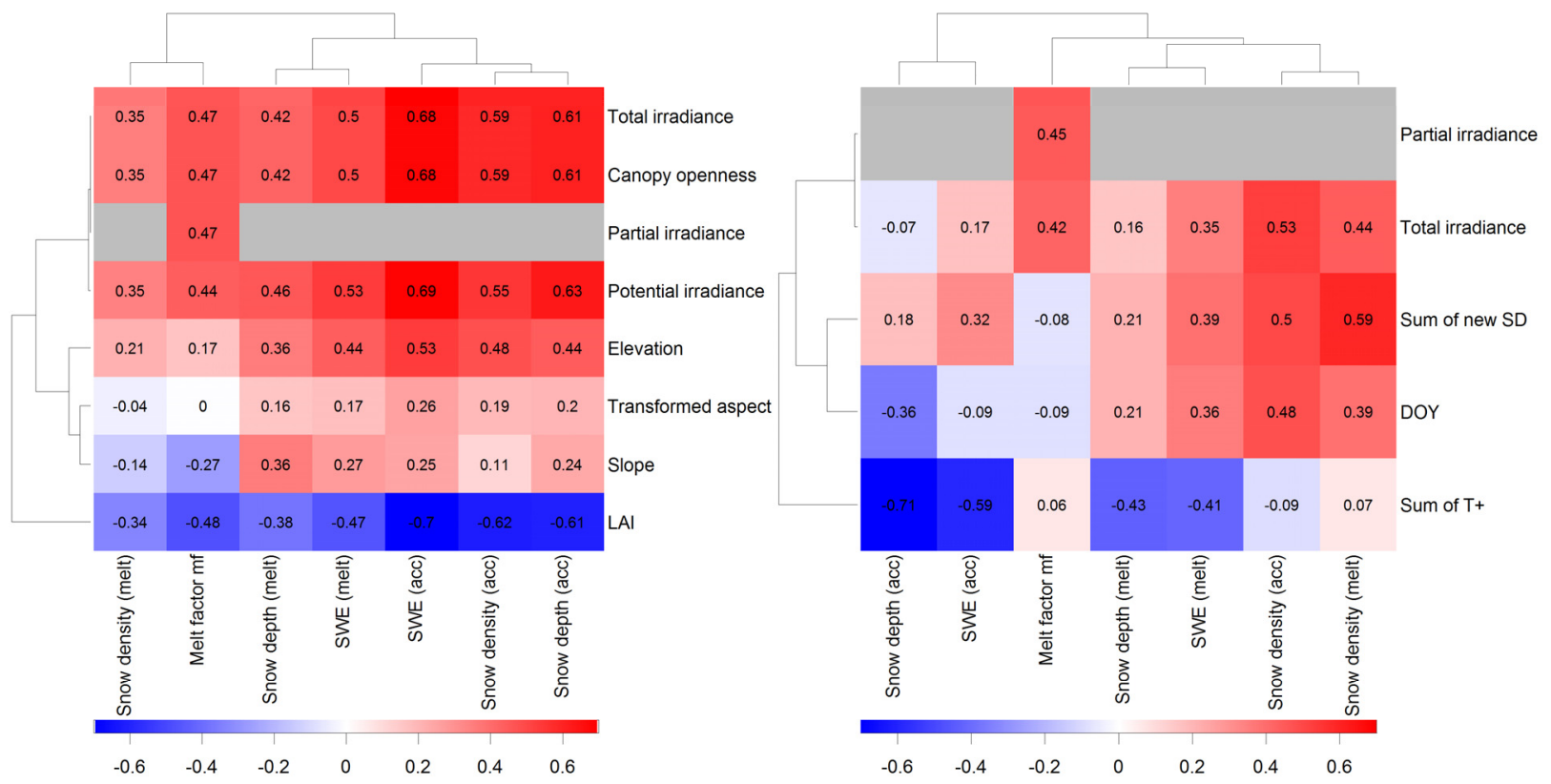

Fig. 4. Heat maps showing Spearman correlation coefficients for all predictors (row) and response variables (columns) for 1) date (left) and 2) locality (right). Colors and numbers represent mean value from all dates/localities. Hierarchical cluster analysis and Euclidean distance were used to show similarity of individual predictors and response variables. Grey color used for NA values.

variations in snow depth and SWE. This was expected since air temperature influences the precipitation phase and thus the snowfall fraction. Similarly, the snow density expectedly increased with DOY of data sampling.

However, the low Spearman correlation between the sum of new SD and snow depth/SWE is surprising (Fig. 4, right). The physical explanation of these low correlations is that the snow depth and SWE were influenced by several periods with air temperature above freezing point and thus partial thawing. Another reason might be the wind redistribution influencing the punctually measured snow depth. Additionally, the calculation of the sum of new SD did not account for canopy interception since data from an automatic snow depth sensor placed in open area were used to calculate this predictor. Moreover, the sum of new SD was calculated based on data from Grosser Arber meteorological station which is placed $100-250 \mathrm{~m}$ higher than our sampling sites (see methods section). Although this predictor describes general snow conditions in the winter period rather than the snow depth evolution in individual sampling site, the mention difference in elevation and geographical location could produce a considerable uncertainty for result interpretation.

Despite the significance of the correlations, their values are not high which indicates that snowpack distribution is influenced by more than a single variable (maximum explained variability was $71 \%$ for the relation between snow depth and sum of positive air temperature). Additionally, some of the predictors are not mutually independent. Since our focus was primarily on the role of vegetation, LAI and irradiance (both potential and total) seem to be the best parameters to predict the snow depth and SWE, although the differences between individual predictors are not large.

The major importance of canopy parameters followed by topography (elevation) is documented by results from cluster analysis (see the dendrogram in Fig. 4). Canopy parameters and total irradiance are major ones when grouping individual sites into clusters based on site characteristic. The elevation and slope have lower importance.

The sampled data containing time-variant information about meteorological and snow conditions and time-invariant site characteristics were further explored with PCA separately for each sampling date. The results from four sampling campaigns made in 2013 were selected as typical representatives and displayed in Fig. 5. Two components were sufficient to explain from $75.4 \%$ (23 Apr 2013) to $82.5 \%$ (6 Mar 2013) of the variance since the eigenvalues of third and other components were less than one. The different site characteristics (represented as arrows) are located in different quadrants and may be correlated to different sampling locations (represented as points). The LAI seems to be the most important factor for forest sites, while topography is more important for open areas and clearings. The LAI is strongly negatively correlated with canopy openness and irradiance since all of the factors were either derived from hemispherical images or these images were used for their calculation. The LAI and potential irradiance explained the majority of the variance of component 1 (Fig. 6). On the contrary, slope and aspect (mutually positively correlated; vectors are close to each other) remained uncorrelated with LAI and irradiance (their vectors are perpendicular to LAI and irradiances vectors) and thus they explained the majority of the variance of component 2 . The melt factor (DDF) was strongly positively correlated with canopy openness and irradiance and negatively correlated with LAI (Fig. 5, sampling date 23 Apr 2013). This indicates that the mentioned factors are the most important factors to explain the melt factor variability.

Sampling points from healthy and disturbed forest sites are grouped in quadrants II and IV. Large open areas are mostly grouped in quadrants I and III as well as sampling locations in clearings. However, all vegetation categories form clearly separate groups. The mentioned distribution does not significantly change in time from snow accumulation (first two sampling dates) to snowmelt period (last two sampling dates). The points are almost uniformly distributed in the plot area especially along the $\mathrm{x}$-axis representing the $\mathrm{PC} 1$. This indicates that the PC 1 explained the majority of the variance of the original dataset.

The Fig. 6 shows the correlation of LAI (zenith angle $60^{\circ}$ ) and potential irradiance (both factors are mutually negatively correlated) to explain the variability of PC 1 . Unlike to Fig. 5 

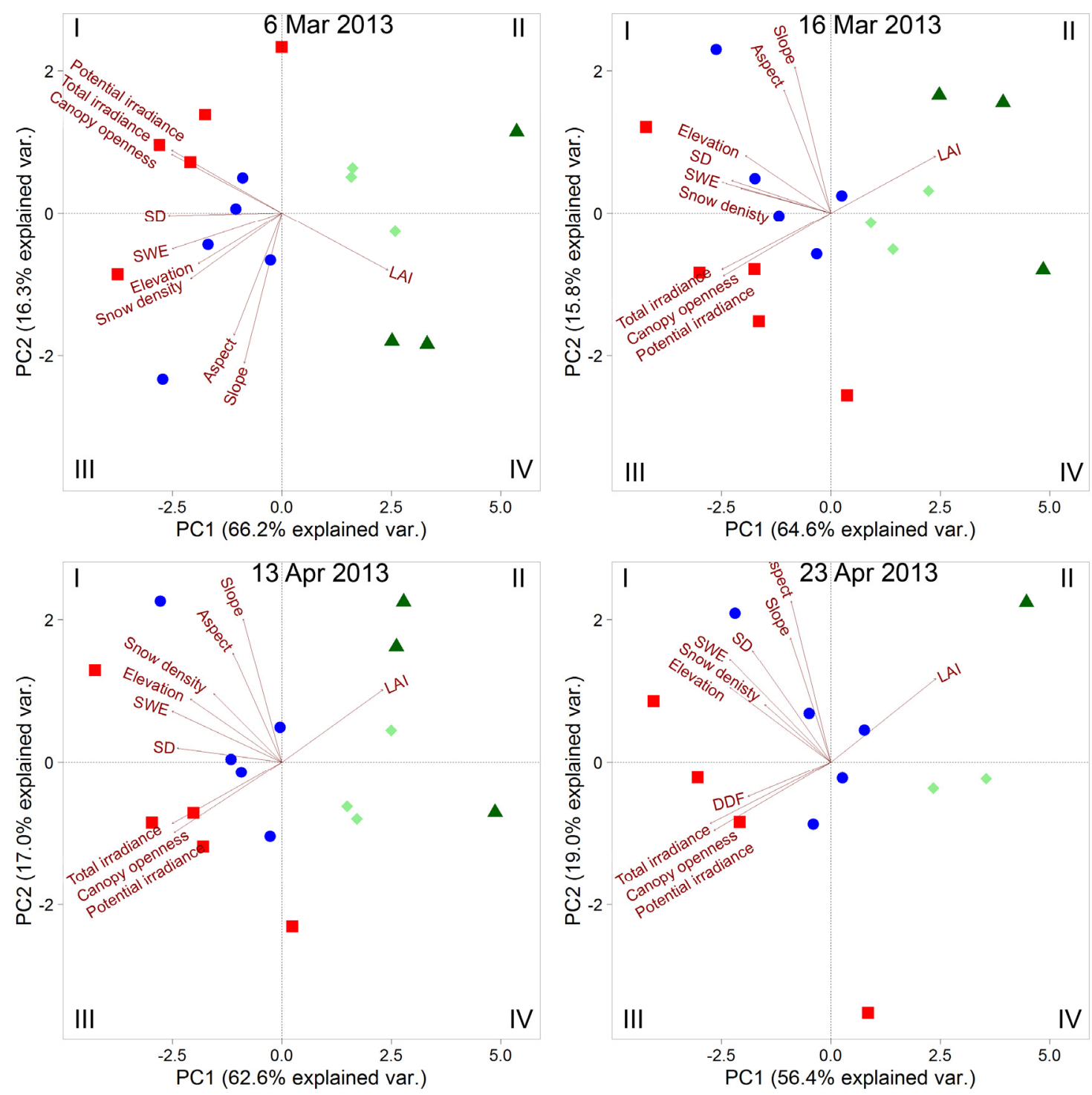

Fig. 5. PCA-biplot for four selected sampling campaigns. Points indicate individual sampling locations (open areas are in red, clearings in blue, healthy forests in dark green and disturbed forests in light green). Arrows indicate eigenvectors for individual site characteristics.
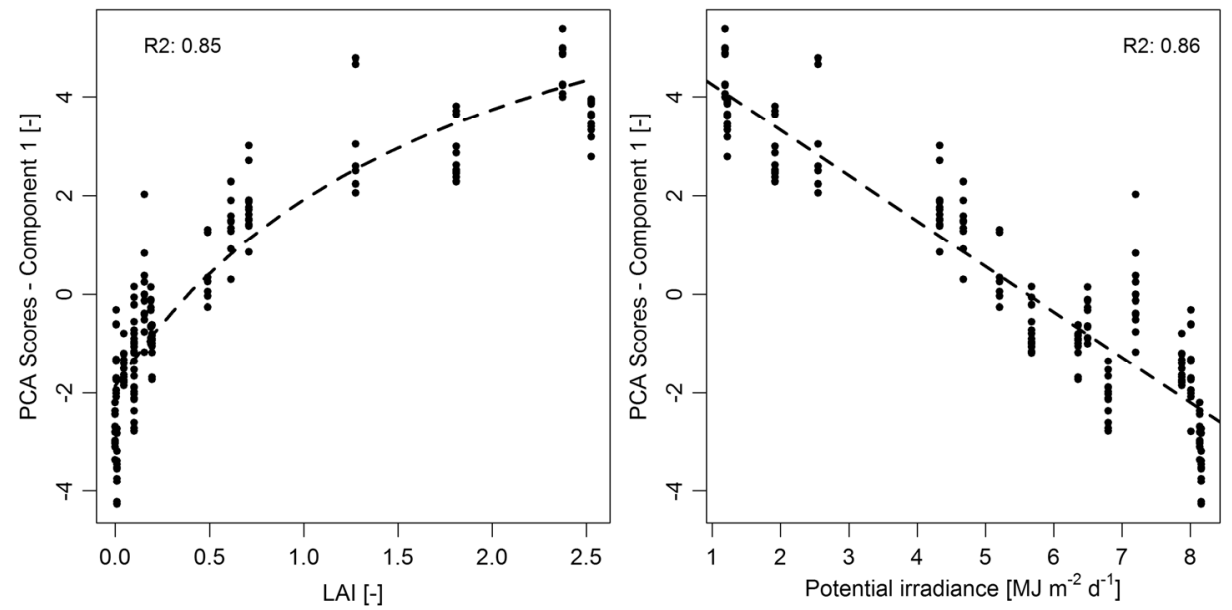

Fig. 6. Correlation between LAI and scores of PC 1 (left panel) and potential irradiance and scores of PC 1 (right panel). Dashed lines represent fitted functions.

which shows only selected sampling dates, Fig. 6 uses the PCA results from all sampling dates and all locations (note that PCA was applied separately for each sampling date). Both the potential irradiance and LAI showed very good fit with the scores of 
PC 1 ( $\mathrm{R}^{2}$ equal 0.85 and 0.86 , respectively). The non-linear relationship in case of LAI indicates a general good explanatory power in case of higher LAI values (typically forest sites) and lower explanatory power in case of LAI $<0.5$ (typically clearings and open areas). Here, the irradiance seems to be better predictor.

\section{The SWE and snow density variability in relation to vegetation}

Several multivariate analyses showed in the previous chapter confirmed the crucial role of canopy structure on the snowpack distribution and snowmelt rates in the study area. Therefore, we performed a further separate analysis focused on canopy parameters and irradiance.

In order to establish a relation between the SWE in open area and forest we used only data from localities with paired measurement of SWE both from open areas/clearings and adjacent forest sites (for position of the paired sampling sites see Fig. 1). The derived prediction model using all pair measurements from 2011 to 2015 enables us to calculate the SWE for forest sites when only the SWE in the open area is measured (Fig. 7). As the dependence is almost linear, we conclude that the SWE in forest sites is on average by $40 \%$ lower than in open areas and clearings and this value does not vary significantly with increasing snow depth or SWE. This difference is almost the same for snow accumulation (40\%) and snowmelt (39\%). However, Fig. 7 shows a large data variability when $79 \%$ of this variability may be explained by vegetation during snow accumulation period and only $49 \%$ during snowmelt.

The same dataset as mentioned above was used to estimate the effect of forest disturbance caused by the bark beetle on snow accumulation in the Ptaci Brook basin. Our data from sites attacked by the bark beetle showed that the combined effect of snow interception and sublimation caused lower SWE differences between open areas and defoliated spruce forest with standing trees compared to the difference between open area and healthy forest $(29.1 \%$ and $44.8 \%$, respectively). It is expected that the interception effect is likely to decrease due to the gradual fall of branches and trunks, and thus snow accumulation increases in locations with disturbed forest.

The snow density is another important parameter which varies in different types of vegetation. Not surprisingly, there was lower snow density during accumulation period compared to ablation period in all vegetation categories (Fig. 8). The lowest snow density was usually in the forest during snow accumulation period, although the variability was relatively high. However, in forests disturbed by the bark beetle, the snow density in snow accumulation period slightly increased while the variability decreased. The highest snow density was mainly in large open areas, probably due to the combined effect of wind (affecting snow crystals structure) and higher incoming solar radiation which caused melt-freeze cycles, and thus the increase in snow density. Both effects causing the higher density in open area than in forest sites are probably more important than opposite effects of higher longwave radiation and canopy drip causing the increase in snow density in forest sites.

\section{Melt factors variability related to different vegetation structure}

The melt factor $m_{\mathrm{f}}$ as a key parameter in degree-day approach shows different snowmelt dynamics (regardless of air temperature) and enables to take into account specific vegetation structure of sampling sites (Fig. 9). Despite the large data

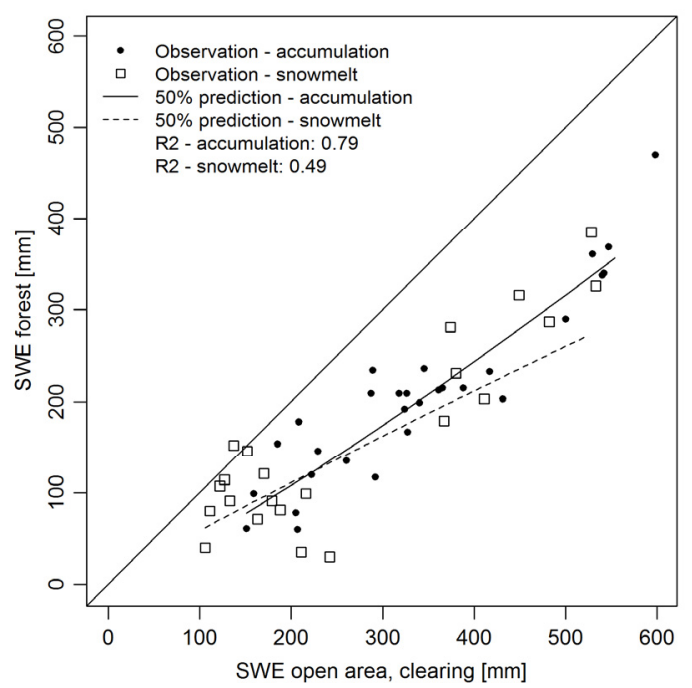

Fig. 7. The SWE in open areas and clearings (x-axis) compared to the SWE measured in the same time in the adjacent forest (y-axis) for all sampling dates. Lines represent $50 \%$ probability of prediction.

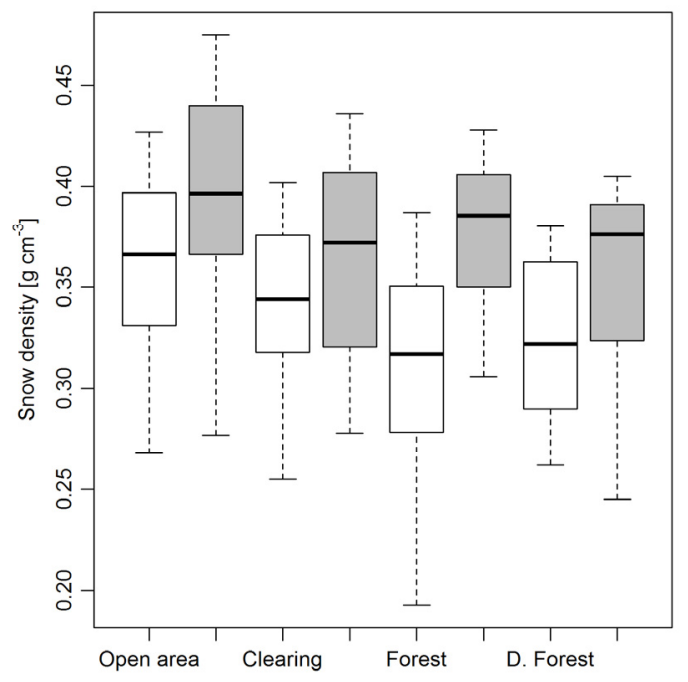

Fig. 8. The snow density in open areas, clearings, forests and disturbed forests. White box plots represent snow accumulation period; grey box plots represent snowmelt period. Boxes represent $25 \%$ and $75 \%$ percentile (with median as a thick line), whiskers represent 1.5 multiplier of interquartile range (IQR).

variability, it is clear that melt factors increased due to increase in incoming solar radiation (caused by sparser canopy cover) and thus a decrease of shading effects. The snow ablation in open areas was almost two times faster compared to forest sites (Table 4). On the contrary, the snow ablation in clearings partly protected against solar radiation was only by $27 \%$ faster than in neighboring forest.

There was lower interception (and thus higher snow accumulation) and faster snow ablation in the disturbed forest, compared to the healthy forest. The snow ablation was by $18 \%$ faster after forest defoliation and we expect an even faster ablation in case of complete forest decline due to further increase in solar radiation. However, the effect of faster snowmelt after forest decline is only temporary since one can expect increasing shading effects and thus decreasing melt factors during forest regeneration and growth. The relatively large variability of $m_{\mathrm{f}}$ values within each vegetation category indicates their limited applicability in other world's regions. 


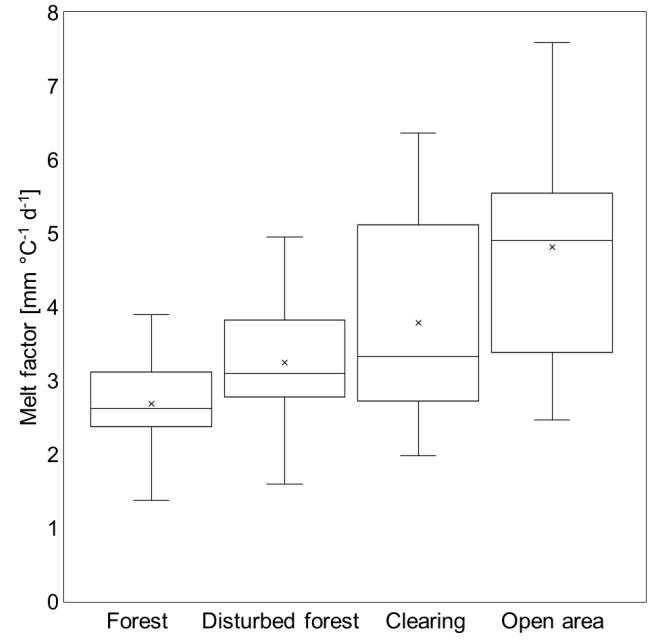

Fig. 9. Melt factors for different vegetation in the study area based on measured data from 2011 to 2015. Boxes represent 25\% and $75 \%$ percentile (with median as a thick line), crosses represent mean values and whiskers represent minimum and maximum.

Table 4. Melt factors for different vegetation in the study area based on measured data from 2011 to 2015 .

\begin{tabular}{lcccc}
\hline Vegetation & Median & Maximum & Minimum & $\begin{array}{c}\text { Increase compared } \\
\text { to the forest }\end{array}$ \\
\hline Forest & 2.6 & 3.9 & 1.4 & $0 \%$ \\
Disturbed forest & 3.1 & 4.9 & 1.6 & $18 \%$ \\
Clearing & 3.3 & 7.2 & 2.0 & $27 \%$ \\
Open Area & 4.9 & 7.6 & 2.5 & $87 \%$ \\
\hline
\end{tabular}

The relation between melt factor $m_{\mathrm{f}}$, LAI and sum of irradiance since the previous date of data sampling (partial irradiance) is shown in Fig. 10. Both LAI and partial irradiance expectedly showed a good relation to the respective melt factor, although there was some portion of variability which cannot be explained by these two predictors. This figure clearly shows that solar radiation is crucial for the variability of $m_{\mathrm{f}}$ and should not be neglected when using the degree day approach. This is especially important for regions where needle forest covers significant part of the study area. Additionally, the results showed that both irradiance and LAI are suitable parameters to estimate the $m_{\mathrm{f}}$ for different vegetation. However, it is important to mention that the irradiance was directly measured only in open area and it was adjusted using canopy openness for specific forest site. Thus both LAI and total irradiance are not mutually independent.

\section{DISCUSSION}

\section{Snow sampling design}

The snowpack variability is extremely large in mountainous conditions, even more than the variability of precipitation. This is caused by the simple fact, that after snow accumulation, there are a lot of subsequent processes influencing the snowpack variability, such as snow redistribution due to wind and avalanches, snow metamorphosis and snowmelt which is influenced by meteorological conditions and site characteristics. It is generally known that the snowpack distribution is difficult to describe by manual point measurements. For partly forested areas, the biggest differences were found when comparing snow amounts deposited in forests and in open areas as documented by this study and several other studies (see e.g. Holko et al., 2009; Jenicek et al., 2015; Jost et al., 2012; Pomeroy et

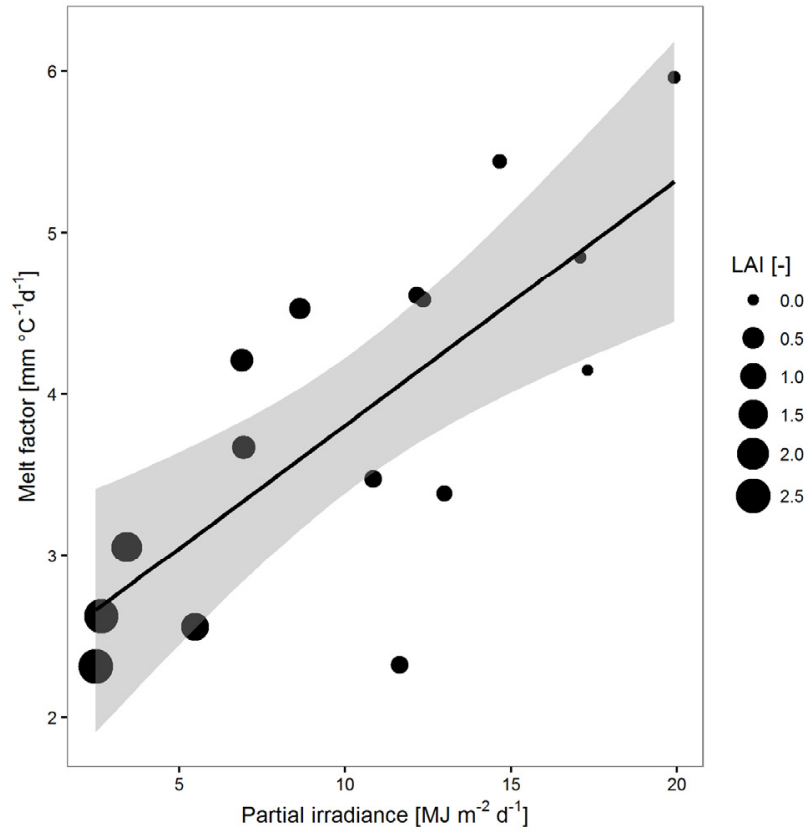

Fig. 10. The relation between melt factor and partial irradiance for sites with different LAI. Grey area represents the $95 \%$ confidence interval. Line represents linear regression with $\mathrm{R}^{2}=0.51$.

al., 2012; Šípek and Tesař, 2014). Obviously, more sampling sites would lead to more reliable results. However, to increase their number is usually hardly possible due to time, financial demands a general accessibility of remote headwater areas, especially during snow season. Therefore, the use of methods applying one or more independent variables leads to applicable results as shown in our study.

Promising results have been also reported using remote sensing approaches such as the use of MODIS satellite data (Duchacek, 2014; He et al., 2014; Krajčí et al., 2016; Parajka et al., 2012), aerial or terrestrial laser scanning (Grünewald et al., 2013; López-Moreno et al., 2015) and unmanned aerial systems (UAV) (De Michele et al., 2016; Lendzioch et al., 2016). We are now testing camera placed on UAV to monitor the snow depth (Lendzioch et al., 2016). However, this approach is still hardly possible to use for distributed sampling design at a catchment scale as used in this study. Additionally, UAV-based sensing monitors snow depth, not snow density and SWE.

Results presented in our study may be influenced not only by selection of sampling points, but also by irregular distribution of sampling campaigns during winter and spring. On the contrary, our data were sampled in five consecutive winter seasons and we were often focused on relative differences of snowpack parameters between sampling dates (such as $m_{\mathrm{f}}$ ). All these facts minimize the uncertainty arising from irregular sampling campaigns.

Most of the correlations found in our study are statistically significant at 0.05 level. However, there is still large variability which cannot be explained by the selected set of predictors. The uncertainty of derived regression models stems partly from imperfect sampling design. Therefore, testing of methods which might be able to measure at a plot or catchment scales such as laser scanning and UAV would be beneficial as documented for example in Lendzioch et al. (2016).

The use of only two hemispherical images per one locality may produce a random error in calculation of the specific parameter. Although we performed particular analysis showing the potential inaccuracies of such approach, Lendzioch et al. 
(2016) tested several methods to derive LAI in the same study area (such as LAI derived from camera placed in UAV, groundbased measurement using Li-Cor plant canopy analyzer and hemispherical photography) and concluded that the hemispherical images provided generally good estimations of LAI at a plot scale. Additionally, different zenith angles used to calculate the LAI ( $60^{\circ}$ in our case) could also influence the results. This issue was addressed e.g. by López-Moreno and Latron (2008) who concluded that optimal zenith angles are in the range 35 $55^{\circ}$ when analyzing the snowpack distribution in a temperate mountain range.

\section{The influence of catchment characteristics on snowpack distribution}

The differences in SWE in the forest and adjacent open area in our study catchment do not significantly vary for winters with high snow storages compared to winters with low snow storages. However, Stähli and Gustafsson (2006) reported decreasing effect of the forest with increasing snow storage in Alptal valley in Switzerland, especially in higher elevations. This contrast might be explained by the shorter observation period of our observations and by the fact that the SWE maximum in Alptal is usually higher than in our study area (600$800 \mathrm{~mm}$ in Alptal; up to $600 \mathrm{~mm}$ in Ptaci Brook catchment). It means we cannot exclude a decreasing effect of interception in Ptaci Brook catchment in case of even higher snow accumulations. However, the difference between the SWE deposited in open area and forest was lower for forest sites with lower LAI typically formed by defoliated forest affected by the bark beetle.

The air temperature used to calculate the melt factors was measured at two climatological stations and it was adjusted to specific sampling site using the site elevation and a lapse rate calculated for each day. Using these daily air temperatures cannot capture their small scale variations due to the small scale variability of topography. This effect might be important in spring especially in clear sky conditions at night and early morning. The minimum temperature strongly varies according to the site topography (frost pockets) which could affect the mean daily air temperature used to calculate melt factors. The above mentioned fact could partially explain a relatively high variability of melt factors within one vegetation category, especially in clearings and large open areas. Here, the melt factors are almost equally distributed within their range. Therefore, it is not fully possible to use derived melt factors as general values to calculate snowmelt in other world regions.

The results from multivariate analyses showed that the LAI was slightly better predictor to explain the SWE during accumulation period, while the total irradiance and potential irradiance were slightly better predictors during snowmelt period. However, the differences are rather minor. Applicable results both for LAI and partial irradiance were achieved with $m_{\mathrm{f}}$ as a response variable. However, it is important to mention that the total irradiance (which was also used to calculate partial irradiance) was directly measured at the meteorological station in the open area. The total irradiance at specific forest site was adjusted according to the canopy openness calculated from the respective hemispherical image. Thus both LAI and total irradiance are not mutually independent and their similarity is logical and expected. Despite the above mentioned uncertainties, we can conclude that parameter derived from hemispherical photography may replace measured incoming solar radiation if this meteorological parameter is not available.

The differences of snow ablation rates between open area and forest were caused mainly by the different amount of solar radiation at the specific site. Faster snowmelt in clearings than in the forest also pointed to the fact that the decrease in shortwave radiation in the forest is more important than the increase in longwave radiation (due to trees as longwave radiation emitters). On the contrary, these effects might change according to the day of year and site conditions, such as the clearing size, distance from surrounding trees or forest gaps (López-Moreno and Latron, 2008; Musselman et al., 2015).

The influence of slope orientation (using the transformed aspect) and slope angle on snowpack distribution and snowmelt dynamics was not proven in our study. The reason is probably the fact that most of the slope aspects in the study area are occurring in NW to NE sector and slope angle maximum is $10^{\circ}$ (with one exception of $20^{\circ}$ ). Therefore, the explanatory power of this predictor is rather limited as also showed in PCA performed in our study. However, the increasing importance of slope orientation on the snowpack distribution especially during snowmelt is expected in case of prevailing E-S-W slopes as proved e.g. by Jenicek et al. (2015).

Despite various predictors used in our study, which describe vegetation, topography and meteorological conditions in the study area, there are some effects, which were not included in this study. One example of such effect is wind. We subjectively observe its impact on snow redistribution at some sampling sites. Therefore, the use a suitable parameter describing this effect (surface curvature or similar) might improve the results especially for open areas during snow accumulation period. However, it would require detailed digital terrain model $(<1 \mathrm{~m}$ resolution) which was not available in the time of the study processing.

The wind has an impact on the small scale variations of turbulent fluxes during snowmelt. Pohl et al. (2006) explored the wind field variability due to topography and found that turbulent fluxes varied up to $20 \%$ from the mean within their research area resulting in relatively high differences in snowmelt by up to $70 \mathrm{~mm}$ over the entire melt period. The described effect is changing in different localities and it is also important for forested areas which markedly influence ground wind speed (Matejka and Jenicek, 2015).

\section{Vegetation structure and its possible impact on runoff}

Despite the relatively simple degree-day approach, our results based on field survey proved an important influence of defoliated forest disturbed by the bark beetle on snow ablation compared to the healthy spruce forest. Our results are in accord with Pomeroy et al. (2012) who used the CRHM model to simulate the impact of forest disturbed be the pine beetle on snow ablation. The decreasing importance of snow interception after spruce forest defoliation was proven in our study, which corresponds to results reported by Pugh and Small (2013) from the western United States. Our results also correspond to conclusions presented by Winkler et al. (2015) who used both measured shortwave radiation and hemispherical photographs to derive the canopy transmittance. However, the reliability of results from the Ptaci Brook catchment could be influenced by the fact that our sampling sites are mostly in disturbed forests with dense treetops, and thus there is still a relatively big amount of snow intercept by the canopy formed by small branches. However, it is expected that the interception effect is likely to decrease due to the gradual fall of branches and trunks. Moreover, we assume that the canopy characteristics of our sites did not change in the period of our sampling campaigns which might be a large simplification especially for sites formed by forests affected by the bark beetle. 
Higher snow accumulations represent a bigger water volume further available for snowmelt and runoff, which does not necessarily mean that total runoff or possible flood peaks would be much higher. As documented by Pomeroy et al. (2012) in their study sites, the total spring and summer runoff volume increased by less than $10 \%$, however, the snowmelt volume increased by $45 \%$ in case of forest burning and logging. Pomeroy et al. (2012) also showed that burning and pine beetle impacts affected more peak flows than seasonal runoff volumes (up to $25 \%$ ). It strongly depended on climatological conditions during snowmelt, such as the air temperature, liquid precipitation (rain-on-snow) and wind. The important effect of needle forest on snowmelt dynamics and thus runoff generation was shown also in modelling experiments performed by Kutlakova and Jenicek (2012).

\section{Practical use of the results}

Although our study mainly confirmed generally known processes influencing snow distribution, the results showed a possible way to improve the estimation of both SWE and snowmelt rates using meteorological, topography and vegetation indices which are relatively simple to derive from basic climate observations and digital terrain model. Such a procedure may be used e.g. by meteorological services and water management to better calculate snow storages in remote mountain areas and it might support existing procedures used by these institutions. Furthermore, it could improve water balance models or enhance reservoirs manipulations.

The results showed that the SWE and snow depth distribution was influenced by several factors which varied in different land covers and changed in time. Therefore, creating groups based either on vegetation categories or dominating snow process (accumulation vs. melting) before creating of a regression model seems to be an effective way to assess the SWE/melt rates variability.

\section{CONCLUSIONS}

We analyzed the snowpack variability in a forested mountain catchment with special interest in the effect of forest structure on both snow accumulation and ablation. Our study was based on repeated distributed measurements of the snow depth and SWE at 16 localities from 2011 to 2015. Based on results, we draw up following conclusions:

- The LAI was slightly better predictor to explain the SWE distribution during accumulation period, while the total irradiance and potential irradiance were slightly better predictors during snowmelt period. However, the differences are rather minor.

- Applicable results both for the LAI and partial irradiance were achieved with the use of melt factor as a response variable. Despite mutual dependence of both parameters, we can conclude that parameters derived from hemispherical images may replace measured incoming solar radiation if this meteorological variable is not available.

- The SWE and snow depth distributions were influenced by several factors which varied in different land covers and which changed in time. Therefore, creating groups either based on vegetation categories or dominating snow process (accumulation vs. melting) seems to be an effective way before the calculation of snow storages in some study area is made. However, despite the significance of the correlations found, there was still large variability which was not explained by the selected set of predictors.

- The combined effect of snow interception and sublimation caused lower SWE difference between open areas and defoliated spruce forest with standing trees compared to the difference between open area and healthy forest $(29 \%$ and $45 \%$, respectively). The snow ablation was by $18 \%$ faster after forest defoliation and we expect even faster ablation in case of complete forest decline. The snow ablation in open areas was almost two times faster compared to forest sites.

Acknowledgement. Support from the Czech Science Foundation (project No. 13-32133S „Headwaters retention potential with respect to hydrological extremes") and European Union (project EU COST Action 1306, no. LD15130 "Impact of landscape disturbance on the stream and basin connectivity") is gratefully acknowledged.

\section{REFERENCES}

Blahušiaková, A., Matoušková, M., 2015. Rainfall and runoff regime trends in mountain catchments (Case study area: the upper Hron River basin, Slovakia). J. Hydrol. Hydromech., 63, 183-192.

Boon, S., 2012. Snow accumulation following forest disturbance. Ecohydrology, 5, 279-285.

Burles, K., Boon, S., 2011. Snowmelt energy balance in a burned forest plot, Crowsnest Pass, Alberta, Canada. Hydrol. Process., 25, 3012-3029.

De Michele, C., Avanzi, F., Passoni, D., Barzaghi, R., Pinto, L., Dosso, P., Ghezzi, A., Gianatti, R., Della Vedova, G., 2016. Using a fixed-wing UAS to map snow depth distribution: an evaluation at peak accumulation. Cryosph., 10, 511-522.

Duchacek, L., 2014. Vertical variability in the position of the zero isochion in geomorphologic regions of Czechia. Geografie, 119, 145-160.

Essery, R., Rutter, N., Pomeroy, J., Baxter, R., Stähli, M., Gustafsson, D., Barr, A., Bartlett, P., Elder, K., 2009. SNOWMIP2: An Evaluation of Forest Snow Process Simulations. Bull. Am. Meteorol. Soc., 90, 1120-1135.

Essery, R., Morin, S., Lejeune, Y., B Ménard, C., 2013. A comparison of 1701 snow models using observations from an alpine site. Adv. Water Resour., 55, 131-148.

Fischer, B.M.C., Rinderer, M., Schneider, P., Ewen, T., Seibert, J., 2015. Contributing sources to baseflow in pre-alpine headwaters using spatial snapshot sampling. Hydrol. Process., 29, 5321-5336.

Frazer, G.W., Canham, C.D., Lertzman, K.P., 1999. Gap Light Analyzer (GLA), Version 2.0: Imaging software to extract canopy structure and gap light transmission indices from true-colour fisheye photographs, users manual and program documentation. Simon Fraser University, Burnaby.

Garvelmann, J., Pohl, S., Weiler, M., 2013. From observation to the quantification of snow processes with a time-lapse camera network. Hydrol. Earth Syst. Sci., 17, 1415-1429.

Grünewald, T., Stötter, J., Pomeroy, J.W., Dadic, R., Moreno Baños, I., Marturià, J., Spross, M., Hopkinson, C., Burlando, P., Lehning, M., 2013. Statistical modelling of the snow depth distribution in open alpine terrain. Hydrol. Earth Syst. Sci., 17, 3005-3021.

He, Z.H., Parajka, J., Tian, F.Q., Blöschl, G., 2014. Estimating degree-day factors from MODIS for snowmelt runoff modeling. Hydrol. Earth Syst. Sci., 18, 4773-4789.

Hock, R., 2003. Temperature index melt modelling in mountain 
areas. J. Hydrol., 282, 104-115.

Holko, L., Škvarenina, J., Kostka, Z., Frič, M., Staroň, J., 2009. Impact of spruce forest on rainfall interception and seasonal snow cover evolution in the Western Tatra Mountains, Slovakia. Biologia, 64, 594-599.

Jenicek, M., Beitlerova, H., Hasa, M., Kucerova, D., Pevna, H., Podzimek, S., 2012. Modeling snow accumulation and snowmelt runoff - present approaches and results. Acta Universitatis Carolinae Geographica, 47, 15-24.

Jenicek, M., Pevna, H., Matejka, O., 2015. Snow accumulation and ablation in three forested mountain catchments. Acta Hydrol. Slovaca, 16, 208-216.

Jenicek, M., Hotovy, O., Matejka, O., 2017. Snow accumulation and ablation in different canopy structures at a plot scale: using degree-day approach and measured shortwave radiation. Acta Universitatis Carolinae Geographica, 52, 1, 51-62.

Jost, G., Weiler, M., Gluns, D.R., Alila, Y., 2007. The influence of forest and topography on snow accumulation and melt at the watershed-scale. J. Hydrol., 347, 101-115.

Jost, G., Dan Moore, R., Smith, R., Gluns, D.R., 2012. Distributed temperature-index snowmelt modelling for forested catchments. J. Hydrol., 420, 87-101.

Kliment, Z., Matouskova, M., Ledvinka, O., Kralovec, V., 2011. Trend analysis of rainfall-runoff regimes in selected headwater areas of the Czech Republic. J. Hydrol. Hydromech., 59, 36-50.

Krajčí, P., Holko, L., Parajka, J., 2016. Variability of snow line elevation, snow cover area and depletion in the main Slovak basins in winters 2001-2014. J. Hydrol. Hydromech., 64, 12-22.

Kucerova, D., Jenicek, M., 2014. Comparison of selected methods used for the calculation of the snowpack spatial distribution, Bystřice River basin, Czechia. Geografie, 119, 199-217.

Kutlakova, L., Jenicek, M., 2012. Modelling snow accumulation and snowmelt in the Bystrice River basin. Geografie, 117, 110-125.

Langhammer, J., Hartvich, F., Kliment, Z., Jeníček, M., Bernsteinová, J., Vlček, L., Su, Y., Štych, P., Miřijovský, J., 2015a. The impact of disturbance on the dynamics of fluvial processes in mountain landscapes. Silva Gabreta, 21, 105-116.

Langhammer, J., Su, Y., Bernsteinová, J., 2015b. Runoff response to climate warming and forest disturbance in a midmountain basin. Water, 7, 3320-3342.

Lendzioch, T., Langhammer, J., Jenicek, M., 2016. Tracking forest and open area effects on snow accumulation by unmanned aerial vehicle photogrammetry. ISPRS - Int. Arch. Photogramm. Remote Sens. Spat. Inf. Sci. XLI-B1, 917-923. DOI: 10.5194/isprs-archives-XLI-B1-917-2016.

López-Moreno, J.I., Latron, J., 2008. Influence of canopy density on snow distribution in a temperate mountain range. Hydrol. Process., 22, 117-126.

López-Moreno, J.I., Revuelto, J., Fassnacht, S.R., AzorínMolina, C., Vicente-Serrano, S.M., Morán-Tejeda, E., Sexstone, G.A., 2015. Snowpack variability across various spatio-temporal resolutions. Hydrol. Process., 29, 12131224.

Lundquist, J.D., Dickerson-Lange, S.E., Lutz, J.A., Cristea, N.C., 2013. Lower forest density enhances snow retention in regions with warmer winters: A global framework developed from plot-scale observations and modeling. Water Resour. Res., 49, 6356-6370.

Matejka, O., Jenicek, M., 2015. An energy-based model accounting for snow accumulation and snowmelt in a coniferous forest and in an open area. In: Voda a Krajina 2015, 1-14.

Molotch, N.P., Meromy, L., 2014. Physiographic and climatic controls on snow cover persistence in the Sierra Nevada Mountains. Hydrol. Process., 28, 4573-4586.

Musselman, K.N., Pomeroy, J.W., Link, T.E., 2015. Variability in shortwave irradiance caused by forest gaps: Measurements, modelling, and implications for snow energetics. Agric. For. Meteorol., 207, 69-82.

Parajka, J., Holko, L., Kostka, Z., Blöschl, G., 2012. MODIS snow cover mapping accuracy in a small mountain catchment - comparison between open and forest sites. Hydrol. Earth Syst. Sci., 16, 2365-2377.

Pohl, S., Marsh, P., Liston, G.E., 2006. Spatial-temporal variability in turbulent fluxes during spring snowmelt. Arct. Antarct. Alp. Res., 38, 136-146.

Pomeroy, J., Fang, X., Ellis, C., 2012. Sensitivity of snowmelt hydrology in Marmot Creek, Alberta, to forest cover disturbance. Hydrol. Process., 26, 1891-1904.

Pugh, E.T., Small, E.E., 2013. The impact of beetle-induced conifer death on stand-scale canopy snow interception. Hydrol. Res., 44, 644-657.

R Core Team, 2016. A language and environment for statistical computing. R Foundation for Statistical Computing, Vienna, Austria. URL https://www.r-project.org/ (accessed 8.1.16).

Revuelto, J., López-Moreno, J.-I., Azorin-Molina, C., AlonsoGonzález, E., Sanmiguel-Vallelado, A., 2016. Small-scale effect of pine stand pruning on snowpack distribution in the Pyrenees observed with a terrestrial laser scanner. Forests, 7, 166.

Seibert, J., Jenicek, M., Huss, M., Ewen, T., 2014. Snow and ice in the hydrosphere. In: Haeberli, W., Whiteman, C. (Eds.): Snow and Ice-Related Hazards, Risks, and Disasters. Elsevier, Amsterdam, pp. 99-137.

Schelker, J., Kuglerová, L., Eklöf, K., Bishop, K., Laudon, H., 2013. Hydrological effects of clear-cutting in a boreal forest - Snowpack dynamics, snowmelt and streamflow responses. J. Hydrol., 484, 105-114.

Schnorbus, M., Alila, Y., 2013. Peak flow regime changes following forest harvesting in a snow-dominated basin: Effects of harvest area, elevation, and channel connectivity. Water Resour. Res., 49, 517-535.

Stähli, M., Gustafsson, D., 2006. Long-term investigations of the snow cover in a subalpine semi-forested catchment. Hydrol. Process., 20, 411-428.

Stähli, M., Jonas, T., Gustafsson, D., 2009. The role of snow interception in winter-time radiation processes of a coniferous sub-alpine forest. Hydrol. Process., 23, 24982512 .

Strasser, U., Warscher, M., Liston, G.E., 2011. Modeling snow-canopy processes on an idealized mountain. J. Hydrometeorol., 12, 663-677.

Šípek, V., Tesař, M., 2014. Seasonal snow accumulation in the mid-latitude forested catchment. Biologia, 69, 1562-1569.

Vlcek, L., Kocum, J., Jansky, B., Sefrna, L., Kucerova, A., 2012. Retention potential and hydrological balance of a peat bog: case study of Rokytka Moors, Otava River headwaters, sw. Czechia. Geografie, 117, 395-414.

Winkler, R., Spittlehouse, D., Boon, S., Zimonick, B., 2015. Forest disturbance effects on snow and water yield in interior British Columbia. Hydrol. Res., 46, 521-532. 